\title{
Assessment of the degree of sloped cropland degradation in typical black soil region
}

\author{
Shouhao Zhang ${ }^{1}$, lei sun ${ }^{1}$, Abdul Hakim Jamshidi ${ }^{1}$, Yong $\mathrm{Niu}^{2}$, Zhaofei Fan ${ }^{3}$, Hongda \\ Zhang $^{1}$, and Xia Liu ${ }^{1}$ \\ ${ }^{1}$ Nanjing Forestry University \\ ${ }^{2}$ Shandong Agricultural University \\ ${ }^{3}$ Auburn University
}

March 20, 2021

\begin{abstract}
A comprehensive evaluation indicator system is needed to provide a integrated assessment of the degree of sloped cropland degradation. We employed bibliometrics to perform statistical analysis on research studies involving cropland degradation. Frequency analysis was then used to identify high-frequency indicators with which to construct a total index set (TIS) for evaluation of the degree of sloped cropland degradation in black soil region. In addition, soil measurement data from sloped cropland in Baiquan and Keshan Counties, Heilongjiang province, China, were used as a basis to construct a minimum index set (MIS). The TIS included A-horizon thickness, clay content, organic matter content, $\mathrm{pH}$, slope gradient, ridge-slope angle, gully density, bulk density, large water-stable aggregate content, soil cation exchange capacity, and crop yield. The first six of these were included in the MIS. In the studied area, undegraded soil, mildly degraded soil, and moderately degraded soil and above accounted for $7 \%, 48 \%$ and $45 \%$ of investigated sloped croplands, respectively. Slope gradient is one of the main factors affecting soil degradation. Soil degradation mainly presented as worsening of soil physicochemical characteristics. In addition, downslope and small-angle ridge cultivation are benefit for soil organic matter maintenance and the soil structure and nutrient retention capacity is better than soil with contour or large-angle ridge cultivation. The reason might be that downslope and small-angle ridge cultivation are usually employed on soil with small slope. The study results provide a scientific basis for improving the quality and productivity of sloped cropland in black soil region.
\end{abstract}

\section{Hosted file}

manuscript.pdf available at https://authorea.com/users/402711/articles/514489-assessment-ofthe-degree-of-sloped-cropland-degradation-in-typical-black-soil-region 